\title{
Community Pharmacists' Perceptions on Ethical Dilemmas, Pharmacy Values and Decision-making
}

\author{
Kingston Rajiah', Rajesh Venkataraman² \\ ${ }^{1}$ Research Scholar, Institute of Pharmacy, Jagdishprasad Jhabarmal Tibrewala University, Jhunjhunu, Rajasthan, INDIA. \\ ${ }^{2}$ Department of Pharmacy Practice, Adichunchanagiri College of Pharmacy, Karnataka, INDIA.
}

\begin{abstract}
Background: Ethics can be predisposed by an individual's values, education, social activities, professional activities, belief, and individual's need. Objective: This study was designed to find out the dilemma in handling ethical issues at community pharmacy settings; to find out the frequency of ethical dilemma at community pharmacy settings; to find out the reasons why community pharmacists may compromise ethical values; to find out how frequent the community pharmacists are involved in ethical dilemma situations. Methods: A descriptive, cross-sectional study was conducted using a validated self-administered questionnaire from March 2016 to December 2017 . The participants were selected using a multi-stage cluster random sampling. Results: In this study, 1057 community pharmacists were approached to participate in this study. Out of this, 742 community pharmacists responded by completing the questionnaire. The response rate in this study is $70.19 \%$. More than half of the issues given were measured as "difficult" and "very difficult" by the community pharmacists. The most common ethical dilemma was fear of breaking trustworthiness which strongly impacts the pharmacist-physician collaborations. 'Carry out patient's request' 'physician's orders' and 'employer's request' were the reasons of community pharmacists compromising the ethical values. Conclusion: Community pharmacists are confronted with numerous ethical problems in their daily work. Most of the pharmacists face the ethical dilemma situations at least once a week in their pharmacies. Community pharmacists compromise on their values and ethical issues not only because of patient's or physician's request but also because of their employers' intrusion.
\end{abstract}

Key words: Community pharmacy, Ethic, Decision-making, India, Pharmacy value.

\section{INTRODUCTION}

The role of the community pharmacist have shifted significantly from the traditional activities of a community pharmacist like extemporary compounding of medications. ${ }^{1}$ Community pharmacists are now the experts in compendium of drugs, accomplishing the physician's prerequisite by providing counseling and advice on use of medications. ${ }^{2}$ They provide right dosage forms, reassuring the quality and efficacy of the medications dispensed by them. ${ }^{3}$ The responsibilities mentioned above are the base for the requirement of ethics guidance for pharmacists. ${ }^{4}$ Pharmaceutical care is the existing practice in community pharmacy in which pharmacists are accountable for drug therapy and to achieve best outcomes that endorse quality of life of the patients. ${ }^{5}$ Certainly ethical issues exist in this new progression in community pharmacy. ${ }^{6}$
Personal ethics is something related to the nature of morality and the choices of being moral, by any human. ${ }^{7}$ Professional ethics integrates the personal, and corporate morals of conduct anticipated from a professional. ${ }^{8}$ Personal ethics makes a substantial part in any discussion on ethics. ${ }^{9}$ Ethics can be predisposed by an individual's values, education, social activities, professional activities, belief, and individual's need. ${ }^{10}$

For a pharmacist, professionalism is one of the most dynamic forces for ethical behavior. ${ }^{11}$ Though there is no universal standard on pharmacists' code of ethics, each country has a guideline on pharmacists' code of ethics and/or code of conduct. ${ }^{12}$ This is to protect the profession as well as the individuals from any kind of misconduct. Professional bodies in respective countries
DOI: 10.5530/ijopp.11.4.36

Address for correspondence: Kingston Rajiah, Research Scholar, Institute of Pharmacy, Jagdishprasad Jhabarmal Tibrewala University, Jhunjhunu, - 333001, Rajasthan, INDIA.

Phone no: +919159309257 Email Id: kingrajiah@gmail.com

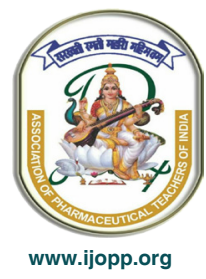


may take action for misconduct or breach of conduct by the pharmacists. ${ }^{4}$ In community pharmacy, prescriptions, medical devices and other over the counter products are dispended by community pharmacists. ${ }^{13}$ Ethical issues do exist while dispensing medications based on prescription and over the counter products. ${ }^{14}$ Community pharmacists are expected to dispense a medication by providing information of drug use, information on adverse effects, interactions of drug with other drugs or with any food, information on appropriate drug dosage, information on drug administration, precautions and contraindications, storage and stability of drugs. ${ }^{15}$ This is as per the code of ethics provided by the Pharmacy Council of India. ${ }^{16}$

Ethics and ethical dilemmas in community pharmacy work place has been seriously interrogated. ${ }^{17}$ Pharmaceutical companies have already been under scrutiny as the physicians continue to be fed and bred by pharmaceutical firms. ${ }^{18}$ Community Pharmacists are the bridging health care professionals between pharmaceutical companies and physicians as they dispense the drugs prescribed by the physicians. ${ }^{19}$ Most community pharmacists work in pharmacies that are independent or part of a franchise of pharmacies. ${ }^{20}$ Community pharmacists usually run a profitable business together with their healthcare facility. ${ }^{21}$ Some community pharmacists work in healthcare sectors and general clinics. Community pharmacists are healthcare professionals who are convoluted in dispensing medications and providing advice on medications. ${ }^{22}$ They also provide management on minor ailments to the patients. ${ }^{21,22}$ Some community pharmacists supply medications by working along with physicians on longtime management plan agreed by the patients. ${ }^{22,23} \mathrm{In}$ these situations, there will be ample of ethical issues or scenarios appear in which community pharmacists are in dilemma and have difficulty in decision making. ${ }^{24}$ In India, the healthcare sector especially the pharmaceutical field in terms of drug dispensing is always questioned on ethics and morality. ${ }^{25}$ So far no study has been reported regarding the ethical dilemmas faced by the community pharmacists in India. This is the first ever study conducted in India on community pharmacist values and ethical dilemmas faced by them. This article is only a part of a broader research work conducted on community pharmacists. This study was designed to identify the socio-demographic characteristics of the community pharmacists; to find out the dilemma in handling ethical issues at community pharmacy settings; to find out the frequency of ethical dilemma at community pharmacy settings; to find out the reasons why community pharmacists may compromise ethical values; to find out how frequent the community pharmacists are involved in ethical dilemma situations.

\section{MATERIALS AND METHODS}

\section{Ethical approval}

This study received ethical clearance by the Institutional ethics committee (IECKDSC\&H) Coimbatore, India (ECR/233/Inst/TN/2013).

\section{Study population and sampling}

A descriptive, cross-sectional study was conducted in Tirunelveli district, Tamilnadu using a validated self-administered questionnaire from March 2016 to December 2017. The participants were selected using a multi-stage cluster random sampling. In Tirunelveli, there are 15 taluks. Each taluk was considered to be an independent cluster. In stage one there was a systematic random selection of the eight taluks from the 15 taluks in Tirunelveli district. In stage two, there was a systematic random selection of five towns in each of those selected taluks. In stage three, by systematic random selection, ten locations in each town were selected. From each selected location, all the community pharmacies available were selected to be part of this study. All the selected community pharmacies were approached to recruit the participants in this study. All those who were $\geq 18$ years of age, registered pharmacists and willing to participate in this study were included as study participants. All those who were not registered pharmacist but working in the community pharmacy and those who were not willing to participate in the study were excluded.

\section{Development of questionnaire}

Questionnaire items were constructed in accordance with the study objectives by conducting an extensive literature review. ${ }^{26}$ The questionnaire was constructed in English as the healthcare professionals have English proficiency. ${ }^{27}$ The questionnaire consisted of 5 sections. Section 1 collected the demographic profile of the participants. Section 2 had 16 scenarios which evaluated the participants' ethical dilemma and decision-making. For each scenario in the questionnaire the participants have to decide how easy or difficult that scenario is for them to make decision on it. A scoring of $1=$ very easy, $2=$ easy, $3=$ neutral, $4=$ difficult, $5=$ very difficult were given for each item in the questionnaire. Section $3 \mathrm{had}$ the same 16 scenarios which evaluated the participants' frequency of ethical dilemma faced. A scoring of $1=$ never, $2=$ few months once, $3=$ once a month, $4=$ once a week, $5=$ once a day were given for each scenario in the questionnaire. Section 4 was to find out the reasons why community pharmacists may compromise ethical values. The participants have to mark one option among the 6 aspects that they feel is the primary reason. In case if they did not find any of the 6 aspects as their primary 
reason there was another option to tick other reasons and write the reason. The 6 aspects are as follows (To protect my job; To carry out physician's orders or request; To respond to colleague request; To meet my employer`s request; To carry out patient's request; Have never had to compromise personal ethical values; Other reasons). Section 5 was to find out how frequent the community pharmacists are involved in ethical dilemma situations, the respondents have to mark one option from the following (Once a week; Once a month; Once in three months; Once in six months; Once in a year; Can't recall; Never had an ethical problem).

\section{Piloting, validation and reliability}

The content of the questionnaire was piloted on 50 respondents. All the data underwent internal consistency (reliability) and content validity prior to the pilot study. For the final analysis, the data of the pilot study were not used. Content validity was done using 3 content experts. Reliability of the questionnaire was assessed and the value of Cronbach-alpha was found to be 0.74 which is consistent.

\section{Data analysis}

Frequencies and percentages were presented for section 4 and 5 of the questionnaire by using descriptive analysis. Total mean score values were presented for section 2 and 3 of the questionnaire. The normality of the data was verified by using Kolmogorov-Smirnov test and the significant value were below 0.05 suggesting violations of the assumption of normality. ${ }^{28}$ As the data distribution was not normal, skewness of the data was analysed. While determining skewness values, if the calculated $z$ value for skewness lie less than the critical values of \pm 1.96 at 0.05 significance level, then the distribution of data is considered normal. ${ }^{29}$ In the current study, the skewness tolerance value was 1.90 and hence the data were considered normally distributed. ${ }^{30}$

\section{RESULTS}

In this study, 1057 community pharmacists were approached to participate in this study. Out of this, 742 community pharmacists responded by completing the questionnaire. The response rate in this study is $70.19 \%$. From this point all the study participants will be denoted as respondents. The details of the frequency and percentage of the socio demographic profile of the respondents have been presented in the Table 1 .

To find out the dilemma in handling ethical issues at community pharmacy settings, total mean scores of the
Table 1: Socio-demographic characteristics of the community pharmacists $(\mathrm{N}=742)$

\begin{tabular}{|c|c|}
\hline Characteristics & n (\%) \\
\hline \multicolumn{2}{|l|}{ Age } \\
\hline $18-30$ years & $145(19.54)$ \\
\hline $31-40$ years & $451(60.78)$ \\
\hline $41-50$ years & $98(13.22)$ \\
\hline$>50$ years & $48(6.46)$ \\
\hline \multicolumn{2}{|l|}{ Work experience } \\
\hline$<5$ years & $101(13.63)$ \\
\hline $5-10$ years & $224(30.18)$ \\
\hline$>10$ years & $417(56.19)$ \\
\hline \multicolumn{2}{|l|}{ Gender } \\
\hline Male & $486(92.45)$ \\
\hline Female & $256(7.55)$ \\
\hline \multicolumn{2}{|c|}{ Education qualification } \\
\hline Diploma & $587(79.12)$ \\
\hline Degree & $155(20.88)$ \\
\hline \multicolumn{2}{|c|}{ Number of Pharmacists per Pharmacy } \\
\hline 1 Pharmacist & $412(55.54)$ \\
\hline 2 Pharmacists & $182(24.52)$ \\
\hline$>2$ Pharmacists & $148(19.94)$ \\
\hline \multicolumn{2}{|c|}{$\begin{array}{l}\text { Distribution of pharmacists according to } \\
\text { the location of the pharmacy }\end{array}$} \\
\hline Rural & $124(16.71)$ \\
\hline Sub-urban & $286(38.55)$ \\
\hline Urban & $332(44.74)$ \\
\hline
\end{tabular}

questionnaire was used. Data have been presented in the Table 2. For the scenario 1 in the questionnaire, the mean score is $3.21 \pm 1.34$. This shows that, for this kind of situation the respondents do not feel easy or difficult. For the scenario 2 in the questionnaire, the mean score is $4.24 \pm 1.53$. This shows that, for this kind of situation the respondents find it difficult to make a decision. For the scenario 3 in the questionnaire, the mean score is $2.52 \pm 1.76$. This shows that, for this kind of situation the respondents find it quite easy to make a decision. For the scenario 4 in the questionnaire, the mean score is $3.48 \pm 1.54$. This shows that, for this kind of situation the respondents neither find it easy nor find it difficult to make a decision. For the scenario 5 in the questionnaire, the mean score is $2.05 \pm 1.71$. This shows that, for this kind of situation the respondents find it easy to make a decision. For the scenario 5 in the questionnaire, the mean score is $3.48 \pm 1.54$. This shows that, for this kind of situation the respondents neither find it easy nor find it difficult to make a decision. For the scenario 6 in the questionnaire, the mean score is $3.93 \pm 1.46$. This shows that, for this kind of situation the respondents 


\section{Table 2: Dilemma in handling ethical issues at community pharmacy settings.}

\begin{tabular}{|c|c|c|}
\hline S No & Ethical Scenario & Mean \pm SD \\
\hline 1 & $\begin{array}{l}\text { A Pharmacist is prevented from dispensing a medicine to the patient due to an administration error in the } \\
\text { prescription }\end{array}$ & $3.21 \pm 1.34$ \\
\hline 2 & $\begin{array}{c}\text { A Pharmacist dispenses a medicine he/she personally considers inadequate for the therapeutic treatment } \\
\text { of the patient, in order to avoid any conflicts with the physician }\end{array}$ & $4.24 \pm 1.53$ \\
\hline 3 & A patient can't afford the necessary drug therapy & $2.52 \pm 1.76$ \\
\hline 4 & $\begin{array}{c}\text { A prescription of the patient can't be filled, due to legal constraints e.g. (inadequate diagnosis, patient's } \\
\text { representative)etc. }\end{array}$ & $3.48 \pm 1.54$ \\
\hline 5 & A pharmacist dispenses a generic drug instead of an original branded medicine & $2.05 \pm 1.71$ \\
\hline 6 & A pharmacist has to dispense a drug therapy which he/she believes will not be beneficial to the patient & $3.93 \pm 1.46$ \\
\hline 7 & A patient is unable to understand health information and advice provided by the pharmacist & $1.81 \pm 1.49$ \\
\hline 8 & $\begin{array}{l}\text { A pharmacist is facing a clearly expressed mistrust of the patient in the prescribed therapy and is required } \\
\text { to act on that }\end{array}$ & $4.34 \pm 1.57$ \\
\hline 9 & A pharmacist performs several tasks simultaneously, while providing pharmaceutical services to a patient & $1.68 \pm 1.63$ \\
\hline 10 & $\begin{array}{l}\text { A pharmacist needs to provide confidential information to the patient when the patient's privacy is } \\
\text { compromised by the presence of other patients }\end{array}$ & $1.64 \pm 1.52$ \\
\hline 11 & A pharmacist is considering violating the rules and regulations in order to perform an act of humanity & $4.19 \pm 1.68$ \\
\hline 12 & A pharmacist is under pressure to achieve daily sales targets for the pharmacy & $1.69 \pm 1.46$ \\
\hline 13 & $\begin{array}{l}\text { A pharmacist needs to inform a patient of the reasons for the prescribed therapy, since the patient doesn't } \\
\text { know his/her diagnosis (irrespective of the reason).The patient may inquire e.g.: "Why do I need to take } \\
\text { this drug?" etc. }\end{array}$ & $3.01 \pm 1.32$ \\
\hline 14 & A pharmacist is selling a falsely advertised dietary supplement. & $2.18 \pm 1.39$ \\
\hline 15 & It is necessary to call into question the competence of a colleague for the sake of the patient's well-being & $3.82 \pm 1.32$ \\
\hline 16 & It is necessary to call into question his/her own competence for the sake of the patient's well-being & $1.51 \pm 1.18$ \\
\hline
\end{tabular}

find it difficult to make a decision. For the scenario 7 in the questionnaire, the mean score is $1.81 \pm 1.49$. This shows that, for this kind of situation the respondents find it very easy to make a decision. For the scenario 8 in the questionnaire, the mean score is $4.34 \pm 1.57$. This shows that, for this kind of situation the respondents find it very difficult to make a decision. For the scenario 9 in the questionnaire, the mean score is $1.68 \pm 1.63$. This shows that, for this kind of situation the respondents find it very easy to make a decision. For the scenario 10 in the questionnaire, the mean score is $1.64 \pm 1.52$. This shows that, for this kind of situation the respondents find it very easy to make a decision. For the scenario 11 in the questionnaire, the mean score is $4.19 \pm 1.68$. This shows that, for this kind of situation the respondents find it very difficult to make a decision. For the scenario 12 in the questionnaire, the mean score is $1.69 \pm 1.46$. This shows that, for this kind of situation the respondents find it very easy to make a decision. For the scenario 13 in the questionnaire, the mean score is $3.01 \pm 1.32$. This shows that, for this kind of situation the respondents do not find it easy or difficult to make a decision. For the scenario 14 in the questionnaire, the mean score is $2.18 \pm 1.39$. This shows that, for this kind of situation the respondents find it easy to make a decision. For the scenario 15 in the questionnaire, the mean score is 3.82 \pm 1.32 . This shows that, for this kind of situation the respondents find it difficult to make a decision. For the scenario 16 in the questionnaire, the mean score is 1.51 \pm 1.18 . This shows that, for this kind of situation the respondents find it easy to make a decision.

To find out the frequency of ethical dilemma at community pharmacy settings, same questionnaire was given to the respondents. . Data have been presented in the Table 3. For the scenario 1 in the questionnaire, the mean score is $3.78 \pm 1.48$. This shows that, this kind of situation is occurring at least weekly once in the pharmacy settings. For the scenario 2 in the questionnaire, the mean score is $2.92 \pm 1.63$. This shows that, this kind of situation is occurring once in a month in the pharmacy settings. For the scenario 3 in the questionnaire, the mean score is $1.68 \pm 1.31$. This shows that, this kind of situation is occurring few months once in the pharmacy settings. For the scenario 4 in the questionnaire, the mean score is $3.56 \pm 1.59$. This shows that, this kind of situation is occurring once a week in the pharmacy settings. For the scenario 5 in the questionnaire, the mean score is $4.98 \pm 1.62$. This shows that, this kind of situation is occurring almost every day in the pharmacy settings. 
Table 3: Frequency of ethical scenarios faced at community pharmacy settings.

\begin{tabular}{|c|c|c|}
\hline S No & Ethical Scenario & Mean \pm SD \\
\hline 1 & $\begin{array}{l}\text { A pharmacist is prevented from dispensing a medicine to the patient due to an administration error in the } \\
\text { prescription }\end{array}$ & $3.78 \pm 1.48$ \\
\hline 2 & $\begin{array}{l}\text { A pharmacist dispenses a medicine he/she personally considers inadequate for the therapeutic treatment of } \\
\text { the patient, in order to avoid any conflicts with the physician }\end{array}$ & $2.92 \pm 1.63$ \\
\hline 3 & A patient can't afford the necessary drug therapy & $1.68 \pm 1.31$ \\
\hline 4 & $\begin{array}{c}\text { A prescription of the patient can't be filled, due to legal constraints e.g. (inadequate diagnosis, patient's } \\
\text { representative)etc. }\end{array}$ & $3.56 \pm 1.59$ \\
\hline 5 & A pharmacist dispenses a generic drug instead of an original branded medicine & $4.98 \pm 1.62$ \\
\hline 6 & A pharmacist has to dispense a drug therapy which he/she believes will not be beneficial to the patient & $2.46 \pm 1.44$ \\
\hline 7 & A patient is unable to understand health information and advice provided by the pharmacist & $1.74 \pm 1.29$ \\
\hline 8 & $\begin{array}{l}\text { A pharmacist is facing a clearly expressed mistrust of the patient in the prescribed therapy and is required to } \\
\text { act on that }\end{array}$ & $2.99 \pm 1.42$ \\
\hline 9 & A pharmacist performs several tasks simultaneously, while providing pharmaceutical services to a patient & $4.98 \pm 1.81$ \\
\hline 10 & $\begin{array}{l}\text { A pharmacist needs to provide confidential information to the patient when the patient's privacy is } \\
\text { compromised by the presence of other patients }\end{array}$ & $4.88 \pm 1.57$ \\
\hline 11 & A pharmacist is considering violating the rules and regulations in order to perform an act of humanity & $2.04 \pm 1.19$ \\
\hline 12 & A pharmacist is under pressure to achieve daily sales targets for the pharmacy & $3.01 \pm 1.72$ \\
\hline 13 & $\begin{array}{c}\text { A pharmacist needs to inform a patient of the reasons for the prescribed therapy, since the patient doesn't } \\
\text { know his/her diagnosis (irrespective of the reason). The patient may inquire e.g.: "Why do I need to take this } \\
\text { drug?" etc. }\end{array}$ & $2.38 \pm 1.84$ \\
\hline 14 & A pharmacist is selling a falsely advertised dietary supplement. & $2.13 \pm 1.42$ \\
\hline 15 & It is necessary to call into question the competence of a colleague for the sake of the patient's well-being & $2.06 \pm 1.33$ \\
\hline 16 & It is necessary to call into question his/her own competence for the sake of the patient's well-being & $2.11 \pm 1.68$ \\
\hline
\end{tabular}

For the scenario 6 in the questionnaire, the mean score is $2.46 \pm 1.44$. This shows that, this kind of situation is occurring few months once in the pharmacy settings. For the scenario 7 in the questionnaire, the mean score is $1.74 \pm 1.29$. This shows that, this kind of situation is occurring few months once in the pharmacy settings. For the scenario 8 in the questionnaire, the mean score is $2.99 \pm 1.42$. This shows that, this kind of situation is occurring once a month in the pharmacy settings. For the scenario 9 in the questionnaire, the mean score is $4.98 \pm$ 1.81. This shows that, this kind of situation is occurring every day in the pharmacy settings. For the scenario 10 in the questionnaire, the mean score is $4.88 \pm 1.57$. This shows that, this kind of situation is occurring almost every day in the pharmacy settings. For the scenario 11 in the questionnaire, the mean score is $2.04 \pm 1.19$. This shows that, this kind of situation is occurring once in a few months in the pharmacy settings. For the scenario 12 in the questionnaire, the mean score is $3.01 \pm 1.72$. This shows that, this kind of situation is occurring every month in the pharmacy settings. For the scenario 13 in the questionnaire, the mean score is $2.38 \pm 1.84$. For the item 14 in the questionnaire, "A pharmacist is selling a falsely advertised dietary supplement" the mean score is $2.13 \pm 1.42$. This shows that, this kind of situation is occurring only a few month once in the pharmacy settings.
For the scenario 15 in the questionnaire, the mean score is $2.06 \pm 1.33$. This shows that, this kind of situation is occurring only a few month once in the pharmacy settings. For the scenario 16 in the questionnaire, the mean score is $2.11 \pm 1.68$. This shows that, this kind of situation is occurring only a few month once in the pharmacy settings.

To find out the reasons why community pharmacists may compromise ethical values the participants mentioned their primary reasons from the 6 aspects provided. Data have been presented in the Table 4. None of the respondents chose the option 'others reasons'. All the respondents chose one aspect from the 6 aspects provided. About 38\% $(n=283)$ respondents chose "To carry out patient's request" as the primary reason for their reasons why community pharmacists compromises on ethical values. This is the top reason among the 6 aspects as well. This shows that, pharmacists want to satisfy their patients in other words customers. So, the ethics does not come in their mind and they just compromise on ethics and values to satisfy their customers. Around $21 \%$ $(n=156)$ respondents indicated that they may compromise on ethical values to carry out the physician's orders or request. This is the second top reason among the 6 aspects. This shows that, pharmacists may follow the 
Table 4: Reasons why community pharmacists may compromise ethical values.

\begin{tabular}{ccc}
\hline Items & $\begin{array}{c}\text { Number of } \\
\text { pharmacists } \\
\text { (N) }\end{array}$ & $\begin{array}{c}\text { Percent } \\
\text { (\%) }\end{array}$ \\
\hline $\begin{array}{c}\text { To protect my job } \\
\text { To carry out physician's orders } \\
\text { or request }\end{array}$ & 156 & 12.53 \\
$\begin{array}{c}\text { To respond to colleague request } \\
\text { To meet my employer's request }\end{array}$ & 59 & 21.02 \\
To carry out patient's request & 124 & 7.95 \\
Have never had to compromise & 283 & 38.14 \\
personal ethical values & 27 & 3.63 \\
$\quad$ Other reasons & 00 & 00 \\
\hline
\end{tabular}

order or it can be a request from the physician irrespective of the issue is ethic is right or not. About 16\% $(n=124)$ of the respondents denoted that they may compromise on ethical values to meet their employer`s request. This shows that, pharmacists may compromise on ethical issues not only because of patient's or physician's request but also their employers who ask them to do so. This is the third top reason among the 6 aspects. About 12\% $(n=93)$ of the respondents may compromise on ethical and pharmacy values just to protect their own job. This indicates that, the pharmacists are afraid that they may lose their job just for the reason of sticking on to the ethical and pharmacy values. This can be the reason they may compromise on the top three reasons mentioned by the respondents here. Almost $8 \%(n=59)$ of the respondents said they may compromise on ethical issue to respond to colleagues' request. The percentage of this aspect is very low which indicated that most of the pharmacist do not compromise for this reason on ethical values. Around $3 \%(n=27)$ of the respondents have never had to compromise on personal ethical values so far. Though this is a rare and intriguing to know that there are some pharmacists who have not compromised on ethical values. However, it is good to know at least some pharmacists are there to stick on ethical and pharmacy values irrespective of any circumstances.

To find out how frequent the community pharmacists are involved in ethical dilemma situations, the respondents have to mark one option from the list given. Data have been presented in the Table 5 . About $58 \%(n=437)$ of the respondents experience ethical dilemma situations one a week. This shows that, pharmacists are put into a situations at least every week which may be due to physicians, or patients or employers or it can be their colleagues. About 20\% ( $n=152)$ of the respondents experience ethical dilemma situations once a month. Around $5 \%(n=39)$ of the respondents face ethical
Table 5: Frequency of community pharmacists' involvement in ethical dilemma situations.

\begin{tabular}{ccc}
\hline Items & $\begin{array}{c}\text { Number of } \\
\text { pharmacists (N) }\end{array}$ & Percent (\%) \\
\hline Once a week & 437 & 58.89 \\
Once a month & 152 & 20.48 \\
Once in three months & 39 & 5.25 \\
Once in six months & 31 & 4.17 \\
Once in a year & 24 & 3.23 \\
Can't recall & 32 & 4.31 \\
Never had an ethical problem & 27 & 3.63 \\
\hline
\end{tabular}

dilemma situations once three months. About 4\% ( $\mathrm{n}=31)$ of the respondents face ethical dilemma situations once in six months. Around 3\% $(n=24)$ of the respondents face ethical dilemma situations once in a year. Around $4 \%(n=32)$ of the respondents cannot recall the ethical dilemma situations they have faced so far. But they may have encountered such situations. Around 3\% ( $n=27$ ) of the respondents never experienced any ethical dilemma situation so far. From the above results we can understand that the pharmacists are facing ethical dilemma most of the time. And very rarely we can find pharmacists who have not experienced any ethical dilemma so far. Hence we can say that pharmacists have continuous ethical dilemma situations.

\section{DISCUSSION}

This study reported on community pharmacists' ethical dilemmas, their values and decision making ability at their daily work. May factors can influence decisionmaking. These factors may include, previous experiences ${ }^{31}$, perceptive prejudices ${ }^{32}$, age and discrete differences ${ }^{33}$, belief in an individual ${ }^{34}$, strong responsibilities, may influence the choices individuals make. Considering the factors that would have influenced the decision making process is imperative to understand the decisions that are made. Explicitly, the factors which may influence the process may also influence the outcomes. This study authorised an indebted awareness on understanding of the ethical aspects of community pharmacists.

The outcomes of this study have revealed that community pharmacists are vulnerable to ethical concerns while practicing in their community pharmacies. As the community pharmacists come in contact with the patients frequently, the ethical responsibilities of the pharmacists escalate. The results showed that more than half of the issues given were measured as "difficult" and "very 
difficult". This shows that community pharmacists are experiencing many perplexing ethical issues in their daily work at community pharmacies. Community pharmacists are in extreme dilemma when handling a prescription from a physician though the medication prescribed is inadequate in therapeutic effect. The dilemma may be due to the fear of breaking trustworthiness which strongly impacts the pharmacist-physician collaborations. ${ }^{35}$ At times, patients are unable to understand the information provided by the community pharmacists. Though the patient(s) is/or unable to understand, the pharmacists decide to dispense the medications. This is a concern as ethics aspect is compromised. As per the code ethics, every pharmacist has to make sure that the patient understand the medication before dispensing the medication. ${ }^{16}$ Though it's ethically incorrect to dispense medication, the community pharmacists claim that they are right as per the law. ${ }^{15}$ This is because the pharmacist has the right to dispense medication to the right person as per the prescription. But the problem is, though the pharmacists need time to provide proper advice to the patients, they are multitasking in a pharmacy as there are usually inadequate number of community pharmacists. Though ethically it may affect the holistic approach of pharmacists, it is not considered as a legal issue, as most of the pharmacies have number of pharmacists as per the rules and regulations. Most of the community pharmacies do not have a separate/privacy counseling room in their community outlet. ${ }^{36}$ But the pharmacists are expected to maintain the privacy of the patients' information and cannot disclose to the other people present at the pharmacy counter. However, due to long queue up of the patients/consumers, the community pharmacists decide to breach the ethical aspects. There are also situations where genuine patient walks into the pharmacy and asks for a prescription drug as it is very urgent. Though the medication may be a prescription medicine but may not cause a serious harm to the patient, the pharmacists may not dispense the medications to the patient as the rules and regulation do not allow them to dispense the medication without a prescription. At these situations the community pharmacists are worried and are in dilemma as it questions their empathy to the patient. Most of the community pharmacists work on target basis and they usually ignore the ethical aspects and hence their behaviour is questionable. The most common ethical dilemma among community pharmacists are when it comes to supplements. Most of the chain pharmacies insists the pharmacists to promote the supplement to the consumers/patients. ${ }^{37}$ The pharmacists are provided with good incentives on achieving the target sales of the supplements. ${ }^{38}$ Hence, the pharmacists decide to promote the dietary supplements as there are no serious side effects by these supplements. Thus the community pharmacists play safe though ethically it is unaccepted. When the competence of a colleague for the sake of the patient's well-being is questioned, the community pharmacists are in dilemma to make a decision. This is because, as the situation talks about a colleagues' competency against the patient's well-being, they wonder whether to go against their colleagues for the sake of patient's well-being or to safe guard their colleagues. However, when the self -competence for the sake of the patient's well-being is questioned, there is no dilemma among the pharmacists as every pharmacist believe he/she is competent enough.

Most of the ethical scenarios are frequently exposed to community pharmacists while practicing in their community pharmacies. Prescription errors are one of the most frequent ethical issues causing ethical dilemma among the community pharmacists. ${ }^{39}$ This can be because of the wrong dose, dosage form or wrong indication in the prescription or it can be carelessness, confusion, neglect, omission or any another blunder in the prescription which occurs frequently. At this situations pharmacists are unable to decide whether to dispense the right medication by self-rectifying it or send the prescription back to the prescriber for the correction. Sometimes, there are situations where patients cannot afford for their medication therapy. At this situations the community pharmacists are in dilemma whether to dispense the medications entirely as per the prescription or to dispense the medications as per the patients' affordability. However, in this study the pharmacists did not face this scenario as their frequent ethical issue. Hence we can say that most of the time patients were able to afford for their drug therapy and situations like these happens rarely. Most of the time the pharmacists are in dilemma whether to dispense a generic drug or a well-known branded drug. ${ }^{40}$ In this study this issue is one of the frequent dilemmas among the community pharmacists. This can be because of various reasons. It can be because the generic drug manufacturers give more offers to the community pharmacists they tend to sell more generic drugs or it can be because the patients prefer cheaper drugs which is not possible by original branded drugs. When a patient does not believe in his/ her medication therapy as he/she thinks the medication will not be beneficial for him/her, it certainly causes dilemma for the pharmacist to make a decision on it. In this study, this is also one of the ethical dilemmas that occurs frequently in community pharmacies. This can be again because of the previous experiences of the patient with any medication prescribed ${ }^{41}$ or the patient may have a chronic condition which has a minimal recovery ${ }^{42}$, or may be due to the religious belief of the patient. ${ }^{43} \mathrm{In}$ this study, the pharmacists had encountered frequent 
ethical situations where the patients do not trust their medications prescribed to them. This can be because the patients these days are losing confident in the medication prescribed to them just because it's not working well ${ }^{44}$ or they don't believe in medications. ${ }^{45}$ As mentioned earlier, most of the pharmacists are multitasking and ethically this is not advisable as this may affect the pharmaceutical care of the patients. Most of the pharmacies may have only one pharmacist available and he/she has to act on different prescriptions. ${ }^{46}$ Results revealed that, community pharmacists tend to breach the rules in order to show their ethics/empathy to the patients by providing controlled medicines at times. In this study, though it's occurring only once in a few months, it is not acceptable as such things should never happen to a patient. Community pharmacists are pressurised to achieve their daily sales targets by the employers of the pharmacies. ${ }^{47}$ If the pharmacy is run by the owners itself, then they themselves want to achieve their target. In our study, the pharmacists have mentioned this happens every month. This may lead to serious issues like dispensing medications which is unnecessary for the patients.

This study results revealed the reasons of community pharmacists which lead to compromise their ethical values. Community pharmacists want to gratify their patients/consumers irrespective of the legal and ethical concerns. This shows that the ethics do not play a key role on decision making of pharmacists. Pharmacists compromise on their values to fulfill their consumers which is a mere marketing strategy than a pharmaceutical care of the patients. Community pharmacists can reevaluate the prescriptions prescribed by any physician for its appropriateness which may be errors of omission or errors of commission. However, community pharmacist are not keen to scrutinize the physician's orders or request. This shows that, pharmacists merely trail the orders from the physicians though there can be ethical issues in it. This may be because the community pharmacies are partially dependent on the physical prescription and collaboration with physicians make their business easy. At times the community pharmacists compromise on the ethical issues when their employers advise them to do so. This happens mostly when the owners are not from pharmacy background but a pharmacist runs the pharmacy with his/her license. This shows that, pharmacists may compromise on ethical issues not only because of patient's or physician's request but also their employers' intrusion. All these can happen just because the community pharmacists want to protect their own job. Job security for the community pharmacists may be the reason for them to compromise on ethical and pharmacy values. However, there still some community pharmacists still existing who does not want to compromise on any of the reasons discussed above. It is intriguing that there are community pharmacists who are not compromised on their ethical values. However, it is good to know that at least some community pharmacists are there to grasp their ethical and pharmacy values irrespective of any circumstances. Changes in humanity and community pharmacy practice ${ }^{48}$ challenge community pharmacists to reconsider and redesign their contributions to the society, thus pharmacy values and ethics of community pharmacists are upheld.

\section{Limitations}

In this study the gender of the respondents were skewed towards male. This is may be because no sampling weights were used though sampling design was complex. Also the analyses were conducted with SPSS, which cannot handle survey weights for inferential statistics, though only the descriptive results have been discussed in this study.

\section{CONCLUSION}

Community pharmacists are confronted with numerous ethical problems in their daily work. Community pharmacists are in ethical dilemma to decide on complex situations. Most of the pharmacists face the ethical dilemma situations at least once a week in their pharmacies. Community pharmacists compromise on their values and ethical issues not only because of patient's or physician's request but also because of their employers' intrusion. This study provided an understanding on the ethical issues in community pharmacies. A further study can investigate the relationships between the ethical dilemma of the community pharmacists and their socio demographic profiles. This will help us to find the predictors which contribute to the ethical dilemma of the community pharmacists.

\section{REFERENCES}

1. Hassali M, Awaisu A, Shafie A, Saeed M. Professional Training and Roles of Community Pharmacists in Malaysia: Views from General Medical Practitioners. Malaysian Family Physician : the Official Journal of the Academy of Family Physicians of Malaysia. 2009; 4(2-3):71-6.

2. Ooi G, Hassali A, Shafie A, Kong D, Mak V, Chua G. Assessment of Community Pharmacy Services in Malaysia: Perspectives from Community Pharmacists, General Practitioners, Consumers and Health Policy Stakeholders. Value in Health 2016; 19(7):A827.

3. Atkinson J, Sánchez Pozo A, Rekkas D, et al. Hospital and Community Pharmacists' Perceptions of Which Competences Are Important for Their Practice. Perrie Y, ed. Pharmacy. 2016; 4(2):21.

4. Noordin MI. Ethics in Pharmaceutical Issues. Contemporary Issues in Bioethics 2012.

5. Grey E, Harris M, Rodham K, Weiss MC. Characteristics of good quality pharmaceutical services common to community pharmacies and dispensing general practices. International Journal of Pharmacy Practice 2016; 24:311-8. 
6. Zunic L, Masic I. What pharmacy practitioners need to know about ethics in scientific publishing. Journal of Research in Pharmacy Practice. 2014;3(4):112-

7. Ayala FJ. The difference of being human: Morality. Proceedings of the National Academy of Sciences. 2010;107:9015-22.

8. Jones M. Reconciling personal and professional values and beliefs with the reality of teaching: findings from an evaluative case study of 10 newly qualified teachers during their year of induction. Teacher Development. 2003;7(3):385-402.

9. Braunack-Mayer AJ. What makes a problem an ethical problem? An empirical perspective on the nature of ethical problems in general practice. Journal of Medical Ethics. 2001;27(2):98-103.

10. Iacovino L. Ethical Principles and Information Professionals: Theory, Practice and Education. Australian Academic \& Research Libraries 2002; 33(2):57-74.

11. Brakel A. Professionalism and Values. Business Ethics: A European Review. 2000;9(2):99-108.

12. International Pharmaceutical Federation. Pharmacist Ethics and Professional Autonomy: Imperatives for Keeping Pharmacy Aligned with the Public Interest. https://www.fip.org/www/uploads/database_file.php?id=358\&table_id= [accessed 13 March 2018].

13. Harvey J, Avery AJ, Ashcroft D, Boyd M, Phipps DL, Barber N. Exploring safety systems for dispensing in community pharmacies: Focusing on how staff relate to organizational components. Research in Social \& Administrative Pharmacy. 2015;11(2):216-27.

14. Salari $\mathrm{P}$, Namazi $\mathrm{H}$, Abdollahi $\mathrm{M}$, et al. Code of ethics for the national pharmaceutical system: Codifying and compilation. Journal of Research in Medical Sciences: The Official Journal of Isfahan University of Medical Sciences. 2013;18(5):442-48.

15. Sinha HK. Role of pharmacists in retailing of drugs. Journal of Advanced Pharmaceutical Technology \& Research. 2014; 5(3):107.

16. Code of pharmaceutical ethics, adopted by Pharmacy Council of India http:// www.ipapharma.org/HTML/communitypharmadivision.html [accessed 13 March 2018].

17. Rodríguez JV, Juričić Ž. Perceptions and attitudes of community pharmacists toward professional ethics and ethical dilemmas in the workplace. Research in Social and Administrative Pharmacy 2017. doi:10.1016/j.sapharm.2017.05.010.

18. Donohue J. A History of Drug Advertising: The Evolving Roles of Consumers and Consumer Protection. The Milbank Quarterly. 2006;84(4):659-99.

19. Mazhar F, Ahmed Y, Haider N, Ghamdi FA. Community pharmacist and primary care physician collaboration: The missing connection in pharmaceutical care. Journal of Taibah University Medical Sciences. 2017;12:273-5.

20. National community pharmacists association, 2009 NCP a Digest sponsored by cardinal health. http://www.ncpanet.org/pdf/digest/digest09_financials.pdf [accessed 13 March 2018].

21. Institute of Medicine (US) Committee on Implications of For-Profit Enterprise in Health Care; Gray BH, editor. For-Profit Enterprise in Health Care. Washington (DC): National Academies Press (US); 1986. 1, Profits and Health Care: An Introduction to the Issues. https://www.ncbi.nlm.nih.gov/books/NBK217897 [accessed 13 March 2018].

22. Al-Mohamadi A, Badr A, Mahfouz LB, Samargandi D, Ahdal AA. Dispensing medications without prescription at Saudi community pharmacy: Extent and perception. Saudi Pharmaceutical Journal. 2013;21:13-8.

23. The role of the pharmacist in the health care system. Essential Medicines and Health Products Information Portal A World Health Organization resource http://apps.who.int/medicinedocs/en/d/Jh2995e/1.6.2.html [accessed 13 March 2018].

24. Fassett WE. Ethics, Law, and the Emergence of Pharmacists' Responsibility for Patient Care. Annals of Pharmacotherapy. 2007;41:1264-7.

25. Sengupta A. "Good pharma" is possible! Indian Journal of Medical Ethics 2016.

26. Crnjanski T, Krajnovic D, Savic M. Pharmacists' Assessment of the Difficulty and Frequency of Ethical Issues Encountered in Community Pharmacy Settings. Science and Engineering Ethics. 2017;1-20.
27. Crnjanski T, Krajnovic D, Tadic I, Stojkov S, Savic M. An Ethical Issue Scale for Community Pharmacy Setting (EISP): Development and Validation. Science and Engineering Ethics. 2015;22(2):497-508.

28. Ghasemi A, ZahediasI S. Normality Tests for Statistical Analysis: A Guide for Non-Statisticians. International Journal of Endocrinology and Metabolism. 2012;10(2):486-9.

29. Kim H-Y. Statistical notes for clinical researchers: assessing normal distribution using skewness and kurtosis. Restorative Dentistry \& Endodontics. 2013;38(1):52-4

30. Hair JF, Black WC, Babin BJ, Anderson RE. Multivariate data analysis. Upper Saddle River, NJ: Pearson Education; 2014

31. Juliusson EÁ, Karlsson N, Gärling T. Weighing the past and the future in decision making. European Journal of Cognitive Psychology. 2005;17:561-75.

32. West RF, Toplak ME, Stanovich KE. Heuristics and biases as measures of critical thinking: Associations with cognitive ability and thinking dispositions. Journal of Educational Psychology. 2008;100(4)30-41.

33. Dewberry C, Juanchich M, Narendran S. Decision-making competence in everyday life: The roles of general cognitive styles, decision-making styles and personality. Personality and Individual Differences. 2013;55(7):783-8.

34. Acevedo M, Krueger JI. Two Egocentric Sources of the Decision to Vote: The Voters Illusion and the Belief in Personal Relevance. Political Psychology. 2004;25:115-34

35. Kruijtbosch M, Göttgens-Jansen W, Floor-Schreudering A, Leeuwen EV, Bouvy ML. Moral dilemmas of community pharmacists: a narrative study. International Journal of Clinical Pharmacy. 2017;40(1):74-83

36. Hattingh HL, Emmerton L, Tin PNC, Green C. Utilization of community pharmacy space to enhance privacy: a qualitative study. Health Expectations. 2015;19(5):1098-110.

37. Kulkarni A, Huerto R, Roberto CA, Austin SB. Leveraging corporate social responsibility to improve consumer safety of dietary supplements sold for weight loss and muscle building. Translational Behavioral Medicine. 2016;7(1):92-7.

38. Miller R, Goodman C. Performance of retail pharmacies in low- and middleincome Asian settings: a systematic review. Health Policy and Planning 2016;31(7):940-53.

39. Cooper RJ, Bissell P, Wingfield J. Dilemmas in dispensing, problems in practice? Ethical issues and law in UK community pharmacy. Clinical Ethics. 2007;2(2):103-8.

40. Albadr Y, Khan TM. Factors influencing community pharmacist decision to dispense generic or branded medicines; Eastern Province, Alahsa, Saudi Arabia. Saudi Pharmaceutical Journal. 2015;23(2):143-6.

41. Beyene K, Aspden T, Sheridan J. Prescription medicine sharing: exploring patients' beliefs and experiences. Journal of Pharmaceutical Policy and Practice. 2016;9(1):23.

42. Jones F. Strategies to enhance chronic disease self-management: How can we apply this to stroke? Disability and Rehabilitation. 2006;28(13-14):841-7.

43. Daher M, Chaar B, Saini B. Impact of patients religious and spiritual beliefs in pharmacy: From the perspective of the pharmacist. Research in Social and Administrative Pharmacy. 2015;11(1):e31-41.

44. Lateef F. Patient expectations and the paradigm shift of care in emergency medicine. Journal of Emergencies, Trauma, and Shock. 2011;4(2):163.

45. Kerse N. Physician-Patient Relationship and Medication Compliance: A Primary Care Investigation. The Annals of Family Medicine. 2004;2(5):455-61.

46. Tweddell SJ, Wright DJ. Community pharmacists will need support after pharmacy cuts announcement, says RPS. The Pharmaceutical Journal 2016.

47. Royal Pharmaceutical Society. Workplace pressures in UK pharmacies must be addressed. The Pharmaceutical Journal 2016 Göttgens-Jansen W, Tuinstra E, Leeuwen EV. Moral Dilemmas in Pharmacy Practice and Professionalism Education. Research in Social and Administrative Pharmacy. 2014;10. 